\title{
Evaluation of risks in environmental and Earth sciences using up-to-date mathematical methods
}

\author{
György Bárdossy \\ Hungarian Academy of Sciences, Budapest
}

\author{
János Fodor \\ Óbuda University, Budapest
}

\begin{abstract}
The article offers a general overview of risk assessment in the environmental and Earth sciences. To begin with natural and man-made hazards are discussed, followed by general definitions and the treatment of uncertainty and risk. The main steps of risk assessment in the Earth sciences are discussed step by step. Finally, the problems of decision-making are briefly treated. To assist the interested reader a comprehensive list of essential references is also presented.
\end{abstract}

Key words: environmental risk and uncertainties; risk assessment methods; decision-making

\section{Introduction}

We use the term risk to express the degree of possibility of a disadvantageous event occurring in the carrying out of our scientific and practical activity. Risks may have one or several outcomes and consequences. Most risks are related to unexpected circumstances of the events.

Risks occur in several fields of human life and society, such as in financial, social, economic, industrial (technical), agricultural, commercial, medical and finally in environmental and Earth-science activities. In this article we discuss only the environmental and Earth-science risks.

In the past it was generally considered that the opinion of experienced experts is sufficient to reliably evaluate the different risks. However, this approach became more and more insufficient and unreliable, as a consequence of the

Addresses: Gy. Bárdossy: H-1055 Budapest, Kossuth tér 18, Hungary. E-mail: bar4750@iif.hu J. Fodor: H-1034 Budapest, Bécsi út 96/b, Hungary. E-mail: fodor@uni-obuda.hu Received: January 13, 2012; accepted: March 14, 2012 
increasingly complicated conditions of the present-day world. For this reason we present in the following an overview of risk analysis, applying up-to-date geomathematical methods. Additionally, we discuss the evaluation of uncertainties related to risk analysis.

\section{The main types of risks in environmental and Earth sciences}

Two main groups can be distinguished: risks related to natural hazards (perils); risks related to human activities.

We distinguish the following natural hazards:

1. earthquakes

2. tsunamis

3. volcanic eruptions, including lahars and ardent volcanic clouds

4. $\mathrm{CO}_{2}$ gases emanating from crater lakes

5. landslides, cold mud flows

6. snow avalanches

7. meteorological perils, such as storms, hurricanes, tornados, typhoons, floods, droughts, etc.

8. methane hydroxide escaping from sub-polar soils and from cold submarine sediments

The main risks of human activities are as follows:

1. Risks of prospecting for mineral resources, e.g. lack of success, failure in suggesting proper mining investment

2. risks of deep-water hydrocarbon prospecting and production

3. gas explosions and fires related to the extraction of gas fields

4. risks of mining activities: e.g. pit-gas explosions, water inrush, environmental contamination during gold extraction by cyanide, consequences of underground collapses

5. risks of radioactive contamination by nuclear power plants

6. risks of contamination by toxic waste

7. risks of safety of radioactive waste disposal

8. risks of displacement of industrial by-products, such as red mud disposal at aluminum plants

\section{The main goals of risk assessment in the above-listed topics}

Natural hazards are too large to be eliminated or mitigated. The main goal of risk assessment is the early warning of the community/communities concerned. The primary goal of the Earth sciences is to clarify the reasons and main features of the given natural hazard, particularly the expected maximum of the peril and its periodicity (repetition in time). 
1. Earthquakes. The science of seismology has made important progress in the last years, but early warning is still an unresolved issue. Areas of high, medium and low seismicity have been delineated all over the Earth. The frequency (recurrence) of earthquakes was determined for all areal units, but the determination of the exact time of future earthquakes remains unresolved. The main constituents of early warning are high-precision geodesic measurements (changes in elevation or dip), changes of some geophysical parameters (e.g. electric conductivity, electromagnetic waves of ultra-short wavelength, etc.), increase of radon-gas concentration, and disquiet of some animals (Varga 2011). However, in our opinion the most important indicator is an increase of local terrestrial tension. According to recent experiences of French seismologists, the analytical comparison of past seismograms of the given area can also be a good indicator of future earthquakes (Pino 2011). The consequences of the earthquakes can be diminished by special construction technologies. Additional risks of earthquakes are the fires starting in the damaged localities. It is significant that earthquakes have resulted so far in the highest losses of human life, such as 830,000 lives in China in 1556, and 243,000 lives in 1976.

2. Tsunamis. They are consequences of sub-oceanic earthquakes. In the last years the United States successfully developed an active "early warning system" for tsunamis. It works by submarine pressure-measuring stations and by highprecision surface-change measuring systems from satellites. This warning system has been applied successfully in the area of the Pacific Ocean.

3. Volcanic eruptions. Large cities and villages situated in the vicinity of acting volcanoes constitute a significant risk. As a consequence, several million people actually live in areas of great volcanic peril. Volcanic eruptions can only be announced some days before the eruption. The strongest indicator of a coming eruption is increasing seismic activity in the vicinity of the volcano. Longperiodic seismic movements are the best indicators. High-precision geodesic measurements also contribute to early warning by indicating changes in elevation and dip of the surface in the vicinity of the volcano. An additional indicator is the increase of heat flux. Special monitoring of the above-mentioned indicators by satellite measurements is also very useful. Ardent volcanic clouds are a particularly dangerous type of volcanic eruption. They consist of very hightemperature volcanic gases and of fine-grained pyroclastic particles. The speed of such a cloud can reach $200 \mathrm{~km} /$ hour up to $10-15 \mathrm{~km}$ around the eruption center. It is very fortunate that they occur relatively rarely. In 1992 the eruption of the Mount Pelée volcano on Montserrat Island (Antilles) produced an ardent volcanic cloud that killed 29, 000 people in a few hours.

The largest volcanic eruptions in the history of the Earth occurred in the distant geologic past: at the Triassic / Jurassic boundary in the southern part of Brazil, in the Permian in Siberia, in the Late Cretaceous in India, in Canada near Lake Superior and finally in the southeastern part of the United States. These eruptions led to the covering by basaltic lava flows of several million square 
kilometers in each area. We do not understand the mechanism of these huge eruptions and the reasons why they were not repeated since that time. They are considered as a potential peril, and would lead to terrible devastation and mass killings should they occur in our time.

4. Emanations of $\mathrm{CO}_{2}$ gas from volcanic lakes. They are highly dangerous as they occur in the lakes of extinct volcanoes. Heavy rains or storms are the reasons for the emanation of the gas which has accumulated near the bottom of the volcanic lakes. Good examples of the danger are the volcanic lakes in Cameroon. The emanation of $\mathrm{CO}_{2}$ from Lake Nyon killed 1,750 people in one night in 1984. Similar volcanic lakes exist in several other countries. For this reason it is highly desirable to develop an early warning system for the risk of this peril.

5. Landslides and cold mud flows. The risks of these phenomena can be determined by rock-mechanical measurements and by the methods of engineering geology. They are generally triggered by heavy rains. In Hungary Újvári elaborated a new method for the evaluation of landslide risks by applying fuzzy and neuro-fuzzy methods of evaluation (Újvári 2007). The evaluation is more difficult when the landslides are triggered by earthquakes. A good example is the earthquake which occurred in 2001 in El Salvador. The landslide triggered by the earthquake covered parts of the city of Santa Tecia with about $30,000 \mathrm{~m}^{3}$ of clayey mud, killing 580 people.

The largest catastrophe caused by a cold volcanic mud-flow occurred in 1965 in Colombia. The eruption of the volcano Nevado del Ruiz melted the snow on the side of the volcano. The resulting cold mud flow covered the city of Armero, killing more than 23,000 people. At the time the risk of such a catastrophe was not realized by the local authorities, which explains the high number of causalities. A monitoring and early warning system has been elaborated since this catastrophe.

6. Snow avalanches represent high risks in localities of winter sports for people leaving protected skiing slopes. In a few cases snow avalanches covered parts of localities, as in 1995 in Tirol (Austria), when seven houses were covered and destroyed by a large avalanche, killing 40 people. Since that time a risk assessment was carried out and a corresponding monitoring system was established.

7. Emanation of methane from gas fields. In some places there is a risk of explosion of leaked gas at the surface. An example of such a catastrophe was the gas explosion at the Buncefield gas field in Herefordshire (England) in 2005, followed by a large fire.

8. Meteorological risks. The most dangerous of these are the hurricanes, occurring most frequently in the Gulf of Mexico. The hurricane called Katrina devastated the city of New Orleans in 2005, killing 1,300 people and destroying a large number of oil and gas-producing platforms in the Gulf. The estimated loss exceeded 100 billion dollars. Since that time great efforts have been undertaken by the United States to elaborate an early warning system through monitoring by airplanes and satellites. This system seems to work successfully. Hurricanes will 
occur again in the Gulf of Mexico and in other tropical areas. Thus the importance of such a system is evident.

9. Methane hydroxide releases. Huge amounts of methane hydroxide occur in soils of subarctic regions, surpassing 400 gigatons according to first-order estimates. Further quantities occur in shallow subarctic submarine sediments. The methane hydroxide may escape with an increase in temperature. The risk consists in the large-scale emanation of this gas and its effect on the climate.

The magnitude of consequences of the risks listed above also depends on the preparations of the local community/communities. The consequences can be considerably diminished for well-prepared communities, while unprepared ones may suffer high losses. As an example, the earthquake and the resulting tsunami off Sumatra Island in 2004 killed 230,000 people and caused immense destruction, as the communities of the area were completely unprepared.

\section{The main goals of risk assessment in cases of human activity}

In these cases the consequences can be reduced or entirely eliminated by corresponding risk assessments. The main types of risk assessments - as listed above - are as follows:

1. Risks of prospecting mineral resources. The optimum level of prospecting can be determined by applying the Bayes statistics. The risk of failure can be also diminished by this method.

2. Hydrocarbon exploration. The risks of hydrocarbon exploration have been evaluated in detail (Smalley et al. 2008). The importance of deep-water prospecting has strongly increased in the last years. The exploration and production drilling platforms often encounter high pressures and temperatures. For this reason deep-water activity has the highest rates of risk. The experts opinions applied to date for resolving these problems are increasingly insufficient. An example for this situation was the catastrophe occurring in April 2010 on a drilling platform in the Gulf of Mexico. The gas emanating under high pressure exploded and the platform sank. A large-scale oil contamination occurred in the Gulf and it took several months to close the leak. The catastrophe could have been avoided by applying a thorough geomathematical risk assessment. This is the solution to avoid similar catastrophes in the future.

3. Mining investments. The main goal of risk assessments is to avoid technical risks such as water inrushes, pit-gas explosions, etc. A further requirement is to insure production of the required grades. Reliable geologic and hydrogeological modeling is the basis for these risk assessments.

4. Nuclear power plants. The technical risks of energy production are not part of our competence. On the other hand, the risk analysis of natural perils - such as earthquakes - is of primary importance. The determination of the highest expected magnitude - expressed as maximum horizontal acceleration - is the main goal of the risk assessment. The internationally published assessments 
indicate the number of earthquakes expected in an interval of 100 years separately for each magnitude. In our opinion the linear extrapolation of the registered past data is incorrect, since these events are generally non-linear. The estimated exact time of the next expected earthquake in any given area is generally inexact.

5. The disposal of radioactive wastes is a process of great responsibility. The reliability of safe disposal is evaluated in so-called safety assessments, which are also risk analyses. A correct geologic modeling of the selected site is the basis of the risk assessment. In Hungary particular attention was paid to the uncertainties and risks regarding the disposal of radioactive waste. Traditional statistical, geostatistical and the new possibilistic methods have been applied to handle these problems, particularly in the case of safety assessments of the repositories.

6. Disposal of toxic waste. Large-scale open pits often produce toxic waste disposed around the open pit. The waste can be washed away by large-scale rains and floods. This occurred some years ago in gold mining in Transylvania (Rumania), with the application highly poisonous cyanide. The existing and planned (i.e. Rosia Montana-Verespatak) disposals can be considered to be time bombs.

7. Disposal of industrial by-products. Industrial treatment of natural raw materials often produces large quantities of by-products, such as the red mud of alumina production from bauxite. A particularly large catastrophe occurred in 2010 at Ajka (Hungary), killing several people and destroying more than 200 houses. In our opinion the catastrophe could have been avoided by regularly repeated monitoring and risk analysis.

When evaluating the risks listed above, a predetermined threshold is the starting point of the risk analyses. On the other hand, the maximum values of the risk components are often underestimated and influenced by the economic and monetary views. That is, the professional decisions are revised by budgetary restrictions, neglecting the risk of the worst-case consequences.

\section{Uncertainty and risk}

In risk assessment procedures in general, and with environmental problems in particular, it is not sufficient to be aware of the presence of uncertainties only. It is also critical to identify their main types and understand the differences between them. Aleatory uncertainty refers to the inherent variation that belongs to the environment, or to a physical system or process: the results of similar trials or occurrences differ. In environmental and Earth sciences this is due to spatial and temporal variability. Aleatory uncertainty is also called randomness, variability, stochastic uncertainty, or irreducible uncertainty. Epistemic uncertainty refers to a lack of knowledge about, and the ability to measure and model, quantities or processes of a system or the environment. It is also called subjective uncertainty, reducible uncertainty, or model form uncertainty. In 
environmental and geologic investigations human shortcomings, incompetency or inadequate conditions may occur at all stages. These include the lack of representative sampling, insufficient laboratory measurements, vagueness or ambiguity in the description of non-measurable properties, conceptual and model uncertainties, subjective information, incorrect application of mathematical methods, neglecting the complex data interpretation or using it in incorrect manner, etc.

As was recently emphasized, in uncertainty propagation techniques it is crucial to account for variability and incomplete information separately, even if conjointly (Dubois 2010). In addition to classical probabilistic and statistical methods, there exist less known uncertainty theories and practical methods developed in the past few decades. Appropriate approaches include, among others, possibility theory (Zadeh 1978; Dubois and Prade 1988; Dubois 2006), fuzzy set theory and fuzzy logic (Zadeh 1965), fuzzy geostatistics (Bárdossy A. et al. 1988), probability boxes (Ferson et al. 1999), and imprecise probabilities (Walley 1991). The interested reader can find further details about uncertainties and risks in our book (Bárdossy and Fodor 2004).

For risk assessment, the selection of an appropriate method for handling uncertainty of input parameters depends on the available information. In the case of aleatory uncertainty, if we have sufficient statistical information, then probabilistic methods can be applied. If the information at hand is incomplete, then interval arithmetic (Moore 1966) or possibility theory (Dubois 2010) is applicable.

\section{The risk assessment process}

1. Collecting basic data by representative sampling. Sampling can be considered representative if the obtained input dataset correctly depicts the given object or process, such as a geologic formation, without bias. Data uncertainty must already be taken into consideration at this level.

2. Building geologic model. An appropriate geologic model is a fundamental requirement for obtaining realistic results of risk assessment. The importance of this fact is not always understood. In the geologic model one must take all factors that may affect risk into consideration. The selection of these factors cannot be arbitrary.

3. Building a geomathematical model. A geomathematical model provides a more formal, mathematical representation of the necessarily descriptive geologic model. From traditional statistical measures the determination of the mean, mode, standard deviation and skewness is desirable when one deals with variability. In addition, Monte Carlo simulation or some of its varieties can be used for incorporating parameter uncertainty. Since the results depend highly on the correlation between variables, one must attempt to determine these on the basis of the available information. In the case of aleatory uncertainty, fuzzy 
numbers, probability boxes and possibility distributions should be constructed. Geomathematical modeling of processes uses differential equations.

4. Selecting appropriate geomathematical methods. In the simplest case one can apply frequentist statistical methods, which can be complemented with Bayesian methods (prior and posterior probabilities). For a parameterized model with ill-known parameters, a probability box is the most natural representation (Ferson et al. 1999). Fuzzy arithmetic or fuzzy logic is indispensable when information is incomplete. The application of fuzzy neural networks is especially suitable in the case of complex phenomena (Fullér 2000). The following methods are of great importance in risk analysis of uncertain objects and processes when the joint propagation of imprecision and variability occurs (Baudrit and Dubois 2005). First, the hybrid possibility-probability method, which combines a Monte Carlo technique with the extension principle of fuzzy set theory (Guyonnet et al 2003). Second, the random set approach that uses belief functions (Shafer 1976) to propagate heterogeneous information in a homogeneous framework in two different ways. Third, the dependency bounds convolution method, which can be used to compute extreme upper and lower cumulative distribution functions on results of a probabilistic model, no matter what correlations or statistical dependencies exist among the variables (Baudrit and Duboi 2005). These methods have been applied by the authors to a real case of soil contamination by lead on a brownfield ironworks in the south of France.

At the end one must evaluate whether the selected methods are sufficient for a reliable risk assessment.

5. Application of the selected geomathematical method. It is compulsory to apply the specific rules of the selected method (e.g. in case of fuzzy numbers, the rules of fuzzy arithmetic). Error propagation requires a special methodology for particular methods. This must be indicated in the final result of the calculations.

6. Determining outcomes and their likelihood of occurrence. Risk can be defined as the combination of the likelihood of occurrence of an undesirable event and the severity of the damage that can be caused by this event (Dubois 2010). Determining possible outcomes is a geologic task that is based on the geologic model. In case of variability, the likelihood of occurrence of undesirable events can be determined by statistical methods. The Dempster-Shafer theory (Dempster 1976; Shafer 1976) and copulas (Bárdossy 2008) also have great capabilities in this respect. In the case of uncertainties due to a lack of knowledge there might be overlapping or transition between outcomes; thus non-stochastic methods must be applied (Bárdossy and Fodor 2011).

7. Determining the extent of consequences for each outcome. Consequences can be continuous or discrete variables, which must be taken into account in the assessment. When input data are uncertain, the results are uncertain as well. Sensitivity analysis helps in recognizing the most influential factors on uncertainty of the results. International experience shows that the likelihood of 
occurrence of undesirable events is usually small, but the severity of the damage they can cause is serious.

8. Decision-making. The last step in risk assessment is decision-making: in most cases there is more than one alternative. The decision must be based on the likelihood of undesirable events and their consequences. In Hungarian practice, the decision is made over the product of the severity of the damage with the probability that it can occur. Unfortunately, this is a misleading practice because the meaning of the two numbers is completely different, even if their product is equal. A good example is the safety of nuclear power plants, where the role of the consequence is dominant even for very small probabilities. In the case of natural hazards the "wait and see" decision also implies a risk.

\section{Summary}

The primary goal of this paper was to review uncertainties and risks due to natural variability and human imperfections and incompetency. Then we summarized new, less known methods for risks assessment. Due to space limitations, we could not give a detailed overview of these methods and case studies. This would require writing a separate paper, which we may do in the near future.

\section{Acknowledgements}

The authors are indebted to Róbert Fullér and Zoltán Unger for their helpful reviews.

\section{References}

Aven, T. 2010: On the need for restricting the probabilistic analysis in risk assessments to variability. - Risk Analysis, 30/3, pp. 354-360.

Bárdossy, A., I. Bogárdi, W.E. Kelly 1988: Imprecise (fuzzy) information in geostatistics. Mathematical Geology, 20/4, pp. 287-311.

Bárdossy, A. 2008: Geostatistical interpolation using copulas. - Water Resources Research, 44, pp. $1-15$.

Bárdossy, G., J. Fodor 2004: Evaluation of uncertainties and risks in geology. - Springer, Berlin Heidelberg, $226 \mathrm{p}$.

Bárdossy, G., J. Fodor 2011: Application of mathematical methods in geosciences. - Magyar Tudomány, 172/6, pp. 703-709. (In Hungarian.)

Baudrit, C., D. Dubois 2005: Comparing methods for joint objective and subjective uncertainty propagation with an example in risk assessment. - In: Proc. 4th Int. Symp. on Imprecise Probabilities. - Pittsburgh, Pennsylvania.

Dempster, A.P. 1976: Upper and lower probabilities induced by a multivalues mapping. - Annals of Mathematical Statistics, 38/2, pp. 325-339.

Dubois, D. 2006: Possibility theory and statistical reasoning. - Computations Statistics and Data Analysis, 51, pp. 47-69.

Dubois, D. 2010: The role of epistemic uncertainty in risk analysis. - In: Scalable Uncertainty Management. Lecture Notes in Computer Science, 6379, pp. 11-15. 
Dubois, D., H. Prade 1988: Possibility theory. An approach to computerized processing of uncertainty. - Plenum Press, New York.

Ferson, S., W. Root, R. Kuhn 1999: RAMAS Risk calc. Risk assessment with uncertain numbers. Applied Biomathematics, Setauket, New York.

Fullér, R. 2000: Introduction to neuro-fuzzy systems. - Physica Verlag, Heidelberg.

Guyonnet, D., B. Bourgine, D. Dubois, H. Fargier, B. Cőme, J.P. Chiles 2003: A hybrid approach for addressing uncertainty in risk assessments. - Journal of Environmental Engineering,. 129, pp. 68-78.

Moore, R.E. 1966: Interval analysis. - Prentice-Hall, Englewood Cliffs.

Pino, A. 2011: The analysis of historical seismograms: an important tool for seismic hazard assessment. Case histories from French and Italian earthquakes. - Bulletin de la Société Géologique de France, 182/4, pp. 367-379.

Shafer, G. 1976: A mathematical theory of evidence. - Princeton University Press, Princeton, New Jersey.

Smalley, C.P., S.H. Begg, M. Naylor, S. Johnsen, A. Godi 2008: Handling risk and uncertainty in petroleum exploration and assett management. - AAPG Bulletin, 92/10, pp. 1251-1261.

Újvári, G. 2007: Investigation of the landslide risk with the help of fuzzy and neuro-fuzzy systems. - Geomatematikai Közlemények, 10, pp. 145-158 (in Hungarian).

Varga, P. 2011: Earthquake prediction. - Magyar Tudomány, 172/7, pp. 843-860. (In Hungarian.)

Walley, P. 1991: Statistical reasoning with imprecise probabilities. - Chapman and Hall, Boca Raton.

Zadeh, L.A. 1965: Fuzzy sets. - Information and Control, 8, pp. 338-353.

Zadeh, L.A. 1978: Fuzzy sets as a basis for a theory of possibility. - Fuzzy Sets and Systems, 1, pp. 3-28. 